\title{
Viable bacterial communities on hospital window components in patient rooms
}

\author{
Patrick F Horve ${ }^{\text {Corresp., } 1}{ }^{1}$, Leslie G Dietz ${ }^{1}$, Suzanne L Ishaq ${ }^{1,2}$, Jeff Kline ${ }^{1}$, Mark Fretz ${ }^{3}$, Kevin G Van Den \\ Wymelenberg ${ }^{\text {Corresp. 1, } 3}$ \\ 1 Biology and the Built Environment Center, University of Oregon, Eugene, Oregon, United States \\ 2 School of Food and Agriculture, University of Maine, Orono, Maine, United States \\ 3 Institute for Health and the Built Environment, University of Oregon, Portland, Oregon, United States \\ Corresponding Authors: Patrick F Horve, Kevin G Van Den Wymelenberg \\ Email address: pfh@uoregon.edu, kevinvdw@uoregon.edu
}

Previous studies demonstrate an exchange of bacteria between hospital room surfaces and patients, and a reduction in survival of microorganisms in dust inside buildings from sunlight exposure. While the transmission of microorganisms between humans and their local environment is a continuous exchange which generally does not raise cause for alarm, in a hospital setting with immunocompromised patients, these building-source microbial reservoirs may pose a risk. Window glass is often neglected during hospital disinfection protocols, and the microbial communities found there have not previously been examined. This pilot study examined whether living bacterial communities, and specifically the pathogens Methicillin-resistant Staphylococcus aureus (MRSA) and Clostridioides difficile (C. difficile), were present on window components of exterior-facing windows inside patient rooms, and whether relative light exposure (direct or indirect) impacts bacterial communities on those hospital surfaces. Environmental samples were collected from 30 patient rooms from a single ward at Oregon Health and Science University (OHSU) in Portland, Oregon, USA. Sampling locations within each room included the window glass surface, both sides of the window curtain, two surfaces of the window frame, and the air return grille. Viable bacterial abundances were quantified using qPCR, and community composition was assessed using Illumina MiSeq sequencing of the $16 \mathrm{~S}$ rRNA gene V3/V4 region. Viable bacteria occupied all sampled locations, but was not associated with a specific hospital surface or relative sunlight exposure. Bacterial communities were similar between window glass and the rest of the room, but had significantly lower Shannon Diversity, theorized to be related to low nutrient density and resistance to bacterial attachment of glass compared to other surface materials. Rooms with windows that were facing west demonstrated a higher abundance of viable bacteria than those facing other directions, potentially because at the time of sampling (morning) 
west-facing rooms had not yet been exposed to sunlight that day. Viable $C$. difficile was undetectable, and viable MRSA was detected at very low abundance. Bacterial abundance was negatively correlated with distance from the central staff area containing the break room and nursing station. In the present study, it can be assumed that there is more human traffic in the center of the ward, and is likely responsible for the observed gradient of total abundance in rooms along the ward, as healthcare staff both deposit more bacteria during activities and affect microbial transit indoors. Overall, hospital window components possess similar microbial communities to other previously identified room locations known to act as reservoirs for microbial agents of hospital-associated infections. 
1 Full Title: Viable bacterial communities on hospital window components in patient rooms

2

3 Short Title: Bacteria and Hospital Windows

4

5 Authors: Patrick F. Horve ${ }^{1, *}$, Leslie G. Dietz ${ }^{1}$, Suzanne L. Ishaq ${ }^{1,2}$, Jeff Kline ${ }^{1}$, Mark Fretz ${ }^{3}$, 6 Kevin G. Van Den Wymelenberg ${ }^{1,3^{*}}$

7

8 Affiliations:

$9{ }^{1}$ Biology and the Built Environment Center, University of Oregon, Eugene, OR, 97403

${ }^{2}$ School of Food and Agriculture, University of Maine, Orono, ME, 04469 (current)

11

12

13

14

15

16

17

20

Corresponding authors: *Patrick F. Horve, pfh@uoregon.edu, (541) 346-5647, Biology and the Built Environment Center, University of Oregon, 5231 University of Oregon, Eugene, OR, 97403-5231

*Kevin G. Van Den Wymelenberg, kevinvdw@uoregon.edu, (541-346-5647), Biology and the Built Environment Center, University of Oregon, 5231 University of Oregon, Eugene, OR, $97403-5231$

Author Contributions: SLI, MF, and KVDW conceived of the project scope and MF and KVDW oversaw project and manuscript development. PFH, LD, and SLI performed initial sample processing. PFH performed qPCR and analyzed results. PFH and LD performed library preparation for next-generation sequencing (NGS). PFH performed analysis of amplicon-based sequencing raw data. PFH and LD wrote the initial manuscript and SLI, JK, MF, and KVDW provided significant edits to the manuscript. 
28 Keywords: 16S rRNA gene, environmental microbiology, hospital-associated infections, 29 hospital microbiome, indoor microbial community

30

31 


\section{Abstract}

33 Previous studies demonstrate an exchange of bacteria between hospital room surfaces and

34

patients, and a reduction in survival of microorganisms in dust inside buildings from sunlight exposure. While the transmission of microorganisms between humans and their local environment is a continuous exchange which generally does not raise cause for alarm, in a hospital setting with immunocompromised patients, these building-source microbial reservoirs may pose a risk. Window glass is often neglected during hospital disinfection protocols, and the microbial communities found there have not previously been examined. This pilot study examined whether living bacterial communities, and specifically the pathogens Methicillinresistant Staphylococcus aureus (MRSA) and Clostridioides difficile (C. difficile), were present on window components of exterior-facing windows inside patient rooms, and whether relative light exposure (direct or indirect) impacts bacterial communities on those hospital surfaces.

4 Environmental samples were collected from 30 patient rooms from a single ward at Oregon Health and Science University (OHSU) in Portland, Oregon, USA. Sampling locations within each room included the window glass surface, both sides of the window curtain, two surfaces of the window frame, and the air return grille. Viable bacterial abundances were quantified using qPCR, and community composition was assessed using Illumina MiSeq sequencing of the $16 \mathrm{~S}$ rRNA gene V3/V4 region. Viable bacteria occupied all sampled locations but was not associated with a specific hospital surface or relative sunlight exposure. Bacterial communities were similar between window glass and the rest of the room, but had significantly lower Shannon Diversity, theorized to be related to low nutrient density and resistance to bacterial attachment of glass compared to other surface materials. Rooms with windows that were facing west demonstrated a higher abundance of viable bacteria than those facing other directions, potentially because at the 
55 time of sampling (morning) west-facing rooms had not yet been exposed to sunlight that day.

56 Viable $C$. difficile was undetectable, and viable MRSA was detected at very low abundance.

57 Bacterial abundance was negatively correlated with distance from the central staff area

58 containing the break room and nursing station. In the present study, it can be assumed that there

59 is more human traffic in the center of the ward, and is likely responsible for the observed

60 gradient of total abundance in rooms along the ward, as healthcare staff both deposit more

61 bacteria during activities and affect microbial transit indoors. Overall, hospital window

62 components possess similar microbial communities to other previously identified room locations

63 known to act as reservoirs for microbial agents of hospital-associated infections.

64

65

66 


\section{Background}

68 Hospital-associated infections (HAIs) are a leading cause of hospital patient morbidity and

69 mortality in the United States (Murphy, Whiting \& Hollenbeak, 2007; James, 2013). The five

70 most common hospital-associated infections include: central line-associated blood infections,

71 ventilator-associated pneumonia, surgical site infections, Clostridioides difficile infections

72 (CDI), and catheter-associated urinary tract infections. These conditions cost the U.S. healthcare

73 system approximately $\$ 3.3$ billion annually (Zimlichman et al., 2013) and extend hospital stays

74 by approximately two-fold for patients (Glance et al., 2011). With HAIs increasing overall costs

75 and placing a burden on both the healthcare industry and patients, a further understanding of HAI

76 causes and interventions is warranted. Notably, only $\sim 50 \%$ of HAIs can be attributed to a

77 specific source (Magill et al., 2014). Given that many HAIs are caused by opportunistic

78 pathogens which take advantage of host immune system alterations and disruption of

79 homeostasis, a better understanding of microbial reservoirs in proximity to the patient and

80 transmission dynamics within the hospital may yield a more effective strategy towards reducing

81 incidences.

82

83 Microbial exchange occurs between hospitals and patients. Patients seed hospital rooms with

84 their unique microbial communities (Best et al., 2010; Horve et al., 2019), and are exposed to

85 and colonized by microorganisms from the hospital room itself (Prussin, Garcia \& Marr, 2015;

86 Jou et al., 2015; Mcdonald et al., 2016; Lax et al., 2017). Microorganisms deposited from both

87 current and previous occupants can be aerosolized from surfaces by the daily activities of

88 patients, visitors, and healthcare staff (Rashid et al., 2017) and come into direct contact with

89 occupants, or may resettle on surfaces and among dust where they may survive for months 
90 (Haysom \& Sharp, 2003). While the transmission of microorganisms between humans and their

91 local environment is a continuous exchange which generally does not raise cause for alarm, in a

92 hospital setting with immunocompromised patients, these building-source microbial reservoirs 93 may pose a risk.

94

95 Aerosolization of microorganisms can act as a transmission vector for HAIs (Pierce \& Sanford, 96 1973). Pathogens have been found to be aerosolized from walking (Qian, Peccia \& Ferro, 2014), 97 toilet use (Best, Sandoe \& Wilcox, 2012; Aithinne et al., 2019), and cleaning activities (Best et 98 al., 2010), sending microorganisms throughout the room. Although patient rooms are cleaned 99 following a set protocol, any additional cleaning protocols that are enacted are only done so in 100 response to the patient's diagnosis. If a patient is not diagnosed with a containment-risk 101 pathogen, only the standard cleaning protocols are followed. It has been demonstrated that 102 despite cleaning efforts, pathogens can persist in hospital rooms at concentrations sufficient for 103 transmission (Boyce et al., 2009; Otter, Yezli \& French, 2014). Furthermore, compliance with

104 cleaning protocols has the potential to impact transmission (Alfa et al., 2008; Horve et al., 2019).

105 Often, windows and associated components are absent from hospital disinfection protocols 106 (Mehtar et al., 2018). Due to the potential for microbial dispersal, an understanding of microbial 107 dust communities of all locations within a hospital room is essential.

109 There has been no characterization of the microbial communities of window glass and associated 110 components within hospital rooms. Our previous study demonstrated that light negatively

111 impacts the survival of microorganisms in dust within built environments (Fahimipour et al., 112 2018), and it is postulated that daylighting could be used to control microbial populations 
113 indoors. To better understand the relative risk to patients from patient room windows and

114 associated components, this study sought to identify (1) whether viable (intact) microorganisms

115 were present on window glass, window frame surfaces, and room curtains; (2) whether relative

116 light exposure (direct sunlight or not) was associated with differences in the viable microbial

117 communities on hospital surfaces; and (3) if light exposure would alter the abundance of two

118 high-risk, hospital-associated pathogens; Clostridioides difficile (C. difficile) and methicillin-

119 resistant Staphylococcus aureus (MRSA).

120

121 Material and Methods

122 Sample Collection

123 University of Oregon laboratory personnel trained Oregon Health and Science University

124 (OHSU) medical staff on performing sampling protocols, to reduce interference in patient rooms

125 and protect patient privacy. Environmental sampling does not require Institutional Review Board 126 approval; however, written information on the project including what samples were being

127 collected, how they would be used, and if the samples would impact patient privacy, was

128 disseminated by OHSU medical staff and discussed with patients prior to sampling.

129

130 Samples were collected between 10:00 a.m. and 11:00 a.m. on June 7, 2019, from the 13th floor

131 of Kohler Pavilion (13K) at OHSU in Portland, Oregon, USA (Fig. 1a). All patient rooms have a

132 window with anodized aluminum sill, jamb, and head frame components, and double-pane

133 insulated glazing units (Fig. 1b). Each window includes a vinyl-backed, hanging curtain on a

134 track which extends beyond the window along the entire outer wall, allowing the curtain to be

135 pulled completely away from the window along the wall. Curtains are laundered after a room is 
136 occupied by a patient flagged for a biohazardous infection, such as CDI. Upon patient discharge,

137 OHSU Environmental Services follow biohazardous infection cleaning protocols. Sampling

138 locations within patient rooms included window glass surface (presumed direct sunlight),

139 window-side of the curtain (presumed direct sunlight), patient-side of the curtain (presumed

140 indirect sunlight), glazing-side of the window frame at the sill (presumed direct sunlight), the

141 window frame surface facing into the room at the sill (presumed indirect sunlight), and wood-

142 covered air return grille (Fig. 1b).

143

144 Environmental samples were collected using Copan FLOQSwabs (Copan Diagnostics, Catalog

145 \#519CS01) pre-moistened with sterile 1X phosphate buffered saline (PBS) solution. The

146 sampled area was swabbed using an overlapping, horizontal "S" pattern and a single-use,

147 disposable plastic frame was used to standardize the collection area. Swabbed areas were located

$148152 \mathrm{~cm}$ to $183 \mathrm{~cm}$ off the ground (average person height), with the exception of the air return

149 grilles which were located $30 \mathrm{~cm}$ to $45 \mathrm{~cm}$ off the floor. A total of 182 samples were taken from

15029 patient rooms and one conference room. Five control samples were collected concurrently,

151 comprised of two PBS controls (swab soaked with sterile 1X PBS), an air control (soaked with

152 sterile $1 \mathrm{X}$ PBS and waved in the air for approximately 30 seconds each), and two negative

153 controls swabbed from sampling staff nitrile gloves to account for staff-sourced contamination,

154 resulting in 187 samples total. After collection, swabs were sealed in individual sterile transport

155 tubes with a $2 \mathrm{~mL}$ aliquot of sterile $1 \mathrm{X}$ PBS each and immediately placed into an ice-filled

156 transport cooler.

157

158 Genomic Material Preparation 
159 Following collection, all samples were maintained at $4{ }^{\circ} \mathrm{C}$ and processed in randomized batches

160 within $48 \mathrm{hr}$. Swab tips and $1 \mathrm{~mL}$ of $1 \mathrm{X}$ PBS from the transport tube were placed into a sterile 2

$161 \mathrm{~mL}$ Eppendorf tube and vortexed briefly to resuspend as much dust as possible from the swab

162 tip. The swab tip was then removed from the tube, leaving the $1 \mathrm{X}$ PBS and resuspended dust

163 particles behind. In order to quantify viable cells only, samples were treated with propidium

164 monoazide (PMA) (Nocker et al., 2007). PMA infiltrates dead or damaged cells through

165 disrupted cell walls and membranes and binds to DNA, preventing polymerase-chain reaction

166 (PCR). One $10 \mu \mathrm{L}$ aliquot of 2.5 mM PMA solution (Fisher Scientific, Catalog \#NC9734120)

167 was added to the 1X PBS and dust solution (final concentration of $25 \mu \mathrm{M}$ ), incubated in the dark

168 for $10 \mathrm{~min}$, vortexed briefly, and incubated in blue light using a PMA-Lite LED Photolysis

169 Device (OPE Biotechnology Co., Ltd., Model \#PT-H18A) according to the manufacturer

170 protocol. DNA extractions were performed using DNeasy PowerLyzer PowerSoil Kit (Qiagen,

171 catalog \#12855-100), following manufacturer protocol.

172

173 Molecular Analysis

174 MRSA abundance was quantified using quantitative PCR (qPCR), with DNA standards

175 (Integrated DNA Technologies) comprising a 200 bp segment of the MRSA nuc gene with

176 SANuc F primer (5' - TAAAGCGATTGATGGTGATACG - 3') and SANuc R primer (5' -

177 TTCTTTGACCTTTGTCAAACTCG - 3') (Bamigboye, Olowe \& Taiwo, 2018). Thermocycling

178 conditions were as follows: $95^{\circ} \mathrm{C}$ for $5 \mathrm{~min}, 40$ cycles of $95^{\circ} \mathrm{C}$ for $15 \mathrm{sec}, 60^{\circ} \mathrm{C}$ for $50 \mathrm{sec}$, and

$17972^{\circ} \mathrm{C}$ for $30 \mathrm{sec}$. Clostridioides difficile abundance was quantified using qPCR with DNA

180 standards from Integrated DNA Technologies (Coralville, Iowa, USA) comprising a 186 bp

181 segment of the TcdA gene with TcdA F primer (5' - CAGGACACACAGTGACTGGTAA - 3')

Peer] reviewing PDF | (2020:04:47884:1:1:NEW 11 Jun 2020) 
182 and TcdA R primer (5' - GAACTGCTCCAGTTTCCCAC - 3') that were designed using the

183 National Center for Biomedical Information (NCBI) Primer-Blast tool and the C. difficile TcdA

184 gene. Thermocycling conditions were as follows: $95^{\circ} \mathrm{C}$ for $5 \mathrm{~min}, 40$ cycles of $95^{\circ} \mathrm{C}$ for $15 \mathrm{sec}$, $18560^{\circ} \mathrm{C}$ for $50 \mathrm{sec}$, and $72^{\circ} \mathrm{C}$ for $30 \mathrm{sec}$. Total bacterial abundance was quantified using DNA 186 standards (Integrated DNA Technologies) comprising a $167 \mathrm{bp}$ segment of the 16S rRNA gene 187 using Total Bacteria F SYBR Primer (5' - GTGSTGCAYGGYTGTCGTCA - 3') and Total 188 Bacteria R SYBR Primer (5' - ACGTCRTCCMCACCTTCCTC - 3') (Fahimipour et al., 2018). 189 DNA sequences for standards are provided in Table S1. Thermocycling conditions were as 190 follows: $95^{\circ} \mathrm{C}$ for $5 \mathrm{~min}, 40$ cycles of $95^{\circ} \mathrm{C}$ for $15 \mathrm{sec}, 58^{\circ} \mathrm{C}$ for $50 \mathrm{sec}$, and $72^{\circ} \mathrm{C}$ for $30 \mathrm{sec}$. All 191 qPCR plates were prepared using an Eppendorf epMotion 5075 robot. PowerUp SYBR Green 192 Mastermix (Thermo-Fisher Scientific, Catalog \#A25741) and an ABI QuantStudio3 (Applied 193 Biosystems, Catalog \#A28137) were used to detect amplification of targeted gene regions.

194 Standard curves were generated using serial-dilutions of the synthetic DNA standards of the 195 SANuc gene $\left(\mathrm{R}^{2}=1\right)$, TcdA gene $\left(\left(\mathrm{R}^{2}=0.98\right)\right.$, and 16S rRNA gene $\left(\mathrm{R}^{2}=1\right)$ with known gene 196 sequence copy numbers.

197

198 Genomic DNA was amplified for high-throughput DNA sequencing, targeting the V3/V4 199 hypervariable region of the 16s rRNA gene, using the primers pair 319F/806R (Drewes et al., 200 2017), dual-indexed barcode primers (Integrated DNA Technologies), and NEBNext High 201 Fidelity 2X Mastermix (New England Biolabs, Catalog \#M0541). Thermocycling conditions 202 were as follows: $98^{\circ} \mathrm{C}$ for $5 \mathrm{~min}, 40$ cycles of $98^{\circ} \mathrm{C}$ for $15 \mathrm{sec}, 60^{\circ} \mathrm{C}$ for $50 \mathrm{sec}, 72^{\circ} \mathrm{C}$ for $30 \mathrm{sec}$, 203 with a final elongation of $72^{\circ} \mathrm{C}$ for $2 \mathrm{~min}$. Primer and PCR reagents were removed using Mag204 Bind RxnPure Plus beads (Omega Bio-Tek, Catalog \#M1386). The resulting amplicons were 
205 quantified using Quant-iT dsDNA High Sensitivity Assay Kit (Thermo-Fisher Scientific, Catalog 206 \#Q33120) on a Molecular Devices SpectraMax M5E Microplate Reader and pooled to $40 \mathrm{ng}$ 207 DNA per sample, then sequenced at the University of Oregon's Genomics and Cell

208 Characterization Core Facility (GC3F). Sequencing was performed on an Illumina Miseq using 209 V3 chemistry, generating 2 x 300 nt reads.

210

211 Statistical Analyses

212 Raw Illumina sequence data were filtered, trimmed, and denoised using the $D A D A 2 \mathrm{v} 1.8 .0$ 213 statistical inference algorithm (Callahan et al., 2016b,a) using the R platform (Team \& Others, 214 2013), which identifies ribosomal sequence variants (RSVs). Due to poor sequencing quality, 215 forward reads only were used and were truncated to $125 \mathrm{nt}$, required to have no ambiguous 216 bases, and each read was required to have fewer than two expected errors based on quality 217 scores. Taxonomy was assigned to RSVs using the RDP Bayesian classifier implemented in $218 D A D A 2$ against the Silva (Quast et al., 2013) version 132 reference database. This method is 219 shown to have an accuracy of $77.8 \%$ confidence for sequence queries of $125 \mathrm{nt}$ for identifying 220 taxonomy at the genus level (Wang et al., 2007). Prior to analyses, we removed variants 221 classified as mitochondria or chloroplasts.

223 To remove putative contaminants, we utilized the decontam (Davis et al., 2018) R package, 224 which utilizes statistical inference and sequenced negative controls to identify putative 225 contaminating sequence features from high-throughput sequencing data. The effects of lighting 226 conditions and sampling locations on community compositions were quantified using a 227 permutational multivariate analysis of variance (PERMANOVA) with the vegan package 
228 (Oksanen, 2018) using variance stabilized reads. Pairwise contrasts between treatment groups

229

230

231

232

233

234

235

236

237

238

239

240

241

242

243

244

245 Results

246

24

248

249

250 tests.

were accomplished by performing PERMANOVA analyses with 10,000 matrix permutations for each pair of factor levels. Differential microbial abundance between sampling locations and lighting conditions was performed using the DESeq2 R package on non-rarefied reads (Love, Huber \& Anders, 2014). DESeq2 utilizes shrinkage estimations for dispersions and fold changes for differential analysis of count data, essentially determining when different bacteria are present in significantly different amounts. Significant differences in the distribution of alpha diversity values between each sampling location were tested using two-sample Kolmogorov-Smirnov

\section{Data and Code Availability}

The raw sequencing data from this project have been uploaded to the National Center for Biotechnology Information (NCBI) Sequence Read Archive (SRA) and are freely accesible under BioProject ID PRJNA610453. The code for all analyses and raw abundance data is available at https://github.com/BioBE/Windows-as-Potential-HAI-Reservoirs.

\section{Abundance}

Viable bacteria were found to occupy all locations sampled. There was no significant difference $\left(\mathrm{F}_{3,66}=0.811, \mathrm{p}=0.49\right)$ in viable bacterial absolute abundance between sampling locations within the hospital rooms (Fig. 2a). Across all samples, there was also not a significant difference $\left(F_{1,68}=0.824, p=0.36\right)$ in abundance of viable bacteria between surfaces exposed to 
251 direct sunlight and those which were not exposed to direct sunlight (Fig. 2b). However, sunlight

252 exposure indoors is strongly mediated by window orientation, thus the analysis was further

253 disaggregated by cardinal orientation. Combining samples from all surfaces, rooms with

254 windows that were facing west demonstrated a higher abundance of viable bacteria than those

255 facing northwest $(p=0.00039)$, east $(p=0.035)$, and southeast $(p=0.0065)$ (Fig. $2 c)$. Summary

256 statistics are provided in Table S2. Rooms with the highest bacterial abundance were located

257 directly next to the nurses station, break rooms, and conference rooms (Fig. 3), while rooms

258 located at the ends of hallways demonstrated lower viable bacterial abundance $(\mathrm{p}=0.016)$.

259 Viable $C$. difficile was not detected at any of the sampled locations. Viable MRSA was

260 detectable at very low abundance in $2.4 \%(2 / 83)$ of the samples collected from the curtain in

261 direct sunlight ( $\sim 3$ viable gene copies) and the window sill in direct sunlight ( $\sim 17$ viable gene

262 copies); there was no detectable live MRSA on the glass, window frame, or air return grille.

263

264 Community Composition

265 Overall, there was no significant difference $(\mathrm{p}=0.083)$ in alpha diversity between locations in

266 direct sunlight and those not in direct sunlight (Fig. 4a), as measured by the Shannon Index

267 (Shannon $\mathrm{H}^{\prime}$ ), which incorporates both the richness and evenness of the community. There was

268 no significant difference in diversity at specific locations with presumed differential amounts of

269 sunlight. However, the bacterial communities present on the surface of the glass were

270 significantly $(\mathrm{p}=0.03)$ less diverse than other communities within the patient room (Fig. 4b).

271 There was no significant difference in the observed distribution in diversity values between the

272 windows and the curtain, but a significant difference was observed between the window and air

273 return grille $(\mathrm{ks}, \mathrm{p}=0.048)$ and the window and the window sill $(\mathrm{ks}, \mathrm{p}=0.023)$, indicating 
274 different distributions in alpha diversity by sampling location (Fig. 4b). There were no

275 significant differences in the diversity of the microbial community between the air return grille,

276 the window sill, or either side of the curtain.

277

278 A total of 1,023 unique RSVs were identified across all environmental swabs. The most 279 relatively abundant phyla based on variance stabilized reads were Proteobacteria, Actinobacteria, 280 and Firmicutes, with no major differences at the phylum level based on location within the 281 patient room or presumptive amount of direct sunlight received (Fig. S1c).

282 At the genus level, all locations (Fig. S1d) and lighting conditions (Fig. S1d) were very similar 283 in their overall microbial composition. The Corynebacterium, Methylobacterium, Pseudomonas, 284 and Nocardioides genera were most abundantly represented across all locations and lighting 285 conditions within patient rooms. There were 47 individual genera that were differentially 286 abundant $(\mathrm{p}<0.05)$ across all samples. The air return grille demonstrated a large variety of 287 bacteria that were differentially more abundant (Fig. 5a-c). The surface of the glass also 288 demonstrated a large variety of differentially abundant bacteria. Acidaminococcus, Bilophila, 289 Curtobacterium, Eremococcus, Luteilobacter, Megasphaera, Polymorphobacter, Rheinheimera, Rhodocytophaga, Rothia, Staphylococcus, Stenotrophomonas, and Veillonella were all 291 differentially abundant on the glass compared to the air return grille (Fig. 5c), curtain (Fig. 5d), 292 and window sill (Fig. 5e). There were very few differentially abundant bacteria between 293 locations in direct sunlight and those not in direct sunlight, including increased observed 294 abundance of Bosea and Nesterenkonia in indirect sunlight and decreased observed abundance of 295 Pseudomonas and Veillonella in direct sunlight (Fig. 5f). The relative abundance of discriminant 296 taxa at each location around the windows are shown in Fig. 5g. 


\section{Discussion}

300 To our knowledge, this is the first study which characterizes the microbial communities of

301 hospital windows and components, and acts as a first step toward a better understanding of the

302 relative risk that patient room windows and associated components pose to patients. Using

303 quantitative and qualitative microbial assessment, this study identified (1) viable (intact)

304 microorganisms present on window glass, window frame surfaces, and room curtains; (2) that

305 relative light exposure (direct sunlight vs. indirect sunlight) was associated with changes to the

306 viable microbial communities on hospital surfaces; and that (3) sunlight exposure did not alter

307 the abundance of two high-risk, hospital-associated pathogens, C. difficile and MRSA. However,

308 cardinal direction of the window did have an effect, which implies that there is a time or intensity

309 threshold to sunlight exposure for altering indoor microbial communities. Further, this study

310 suggests a spatial pattern to bacterial abundance based on putative occupancy density, potentially

311 implying that human occupants may have a stronger effect on indoor microbial communities

312 than ambient light exposure.

313

314

315

316 Overall, viable bacterial load was similar across all locations, but lower bacterial diversity was

317 found on the surface of the window glass. We hypothesize nutrient available or surface adhesion

318 might play a role in the reduced richness observed on the glass, but these were not evaluated in

319 the present study. The more abundant bacterial taxa on windows identified in this study are

320 associated with unique, advantageous means of energy production. For example,

Peer] reviewing PDF | (2020:04:47884:1:1:NEW 11 Jun 2020) 
321 Acidaminococcus is able to utilize amino acids as an energy source (Rogosa, 1969) and

322 Polymorphobacter is capable of photosynthetic energy production (Hirose, Matsuura \& Haruta,

323 2016). A previous study of bacterial communities in dust under different lighting conditions

324 suggest that some bacteria can survive in enclosed systems, either as auxotrophs or by

325 cannibalizing other members of the microbial community. The present study did not examine

326 bacterial survival over time, or bacterial metabolism, but this hypothesis represents a clear next 327 step in hospital microbiome research.

328

329 Notwithstanding the differentially abundant bacteria between each of the room surfaces, the 330 overall composition of the bacterial communities are very similar, with very few outlier taxa 331 among the 25 most abundant bacteria, regardless of location or light treatment. Even when 332 comparing these 25 bacteria in each sample that are also considered differentially abundant, very

333 few differences were observed between location and lighting. Based upon this small sample set, 334 neither the lighting condition nor the location demonstrates a significant role in the determination 335 of bacterial community composition. However, the failure to capture a larger number of 336 comparable microbial communities from surfaces in direct and indirect sunlight within the same 337 patient room hinders further analysis into the effect of direct vs. indirect sunlight, warranting 338 further investigation.

339

340 In the present study, west-facing rooms harbored significantly more bacteria than rooms facing

341 other directions, suggesting that sunlight intensity or exposure time is a significant factor in

342 determining the microbial abundance found within patient rooms. Previous studies demonstrated

343 that microbial communities in model buildings were significantly modified by both ultraviolet 
344 and visible spectrum light which mimicked what was found indoors with standard window glass

345 (Fahimipour et al., 2018). All samples were collected between 10 A.M and 11 A.M. PDT. At this

346 time of day, sunlight would have directly entered into rooms, except those facing west. One

347 potential explanation for the observed viable microbial load is that the west-facing rooms had not

348 had sunlight exposure for a longer period of time, and thus viable microbial communities had

349 more time to accrue or recover from the sun exposure of the previous day. This potentially

350 resulted in a higher viable bacteria load during this time of the day compared to the other rooms.

351 However, lacking data on the clinical state of patients, quantification of light exposure in patient

352 rooms, or cleaning records for the period preceding sample collection only permits speculation

353 that a difference in sunlight dosage is responsible for the observed increase in viable bacterial

354 load.

355

356 Rooms located at the ends of hallways demonstrated significantly fewer viable bacteria than

357 more centrally located spaces, suggesting that the increased traffic around the central kiosk from

358 nurses, doctors, providers, administrators, and hospital visitors throughout their daily activities

359 contributes to the higher observed bacterial load. Room occupancy on this ward is high, thus

360 rooms further from the centrally-located nurses' station are typically occupied as often as

361 centrally-located rooms in $13 \mathrm{~K}$ at OHSU. Patients on this ward present with similar medical

362 acuity, and it can be theorized that staff spend similar amounts of time in each room, yet it has

363 been shown that patients further from nursing stations receive less care time and have worse

364 outcomes (Yi \& Seo, 2012; Lu et al., 2014). Thus, it can be assumed that there is more human

365 traffic in the center of the ward, and is likely responsible for the observed gradient of total

366 abundance in rooms along the ward, as healthcare staff both deposit more bacteria during 
367 activities and affect microbial transit indoors. Healthcare staff activities contribute to the spread

368 of bacteria throughout hospital wards (Pittet et al., 1999; Perry, Marshall \& Jones, 2001; March

369 et al., 2010), and previous work has demonstrated that occupancy (Meadow et al., 2015), space-

370 use, and building topology affect indoor microbial communities (Kembel et al., 2014).

371

372 Clostridioides difficile is an anaerobic bacterium that causes extreme dehydration, excessive

373 diarrhea, and colitis (James, 2013; Taylor et al., 2016), and is among the most common causes of

374 HAIs in the United States (Carrico et al., 2013). Viable C. difficile was not detected using qPCR

375 in this study; however, as an obligate anaerobe, $C$. difficile is unable to survive outside of its host

376 in a vegetative state for more than a few hours (Jump, Pultz \& Donskey, 2007). To circumvent

377 this, $C$. difficile forms an endospore, a resilient outer shell, to protect the dormant cell until

378 favorable conditions arise, up to 5 months (Gerding, Muto \& Owens, 2008). In addition to

379 protection from the outside environment, this spore can also make it difficult to extract DNA, 380 potentially preventing quantification.

381

382 MRSA has been linked to bacteremia, endocarditis, and infections of skin and soft tissue

383 infections, bone and joints infections (Turner et al., 2019). MRSA was found in only two

384 samples in the present study, and at low abundance. Staphylococcus aureus (S. aureus) typically

385 has a high minimum infective dose, owing to its need to form a biofilm for both survival and

386 virulence (Greig, Todd \& Bartleson, 2010; Public Health Agency of Canada, 2012). However,

387 this does not preclude the potential that these small communities of MRSA could potentially

388 increase and pose a risk. MRSA is capable of surviving a variety of conditions, and can colonize

389 and remain inside an individual without causing symptoms for months at a time (Public Health 
390 Agency of Canada, 2012; Turner et al., 2019). Even more concerning, communities of S.aureus

391 have demonstrated the ability to participate in a wide variety of horizontal gene transfer,

392 allowing MRSA of varying pathogenicities and transmission capabilities to develop within the

393 hospital room microbiome by interacting with other bacteria (Wielders et al., 2001; Brody et al.,

394 2008; Li et al., 2012; Otto, 2013).

395

396 The results of this study are potentially further influenced by unique patient microbiota (Meadow

397 et al., 2015) which imprint upon the room, rapid patient turnover which may prevent microbial

398 deposition in rooms (Meadow et al., 2015), and the use of harsh cleaning chemicals and different

399 cleaning protocols, all of which presumably alter the total abundance and diversity of the bacterial

400 community within the hospital ecosystem. In particular, bacteria that can survive frequent, harsh

401 cleanings may be better able to withstand variations in environmental conditions within patient

402 rooms (Velazquez et al., 2019). While the unique design and occupancy of individual buildings

403 make it difficult to compare indoor microbial communities between structures, it is important to

404 note that many observational studies of microbial communities within the built environment, such

405 as office spaces and homes, identify thousands of unique taxa (Kembel et al., 2012; Stenson et al.,

406 2019). The present study identified approximately 1000 taxa, despite the high occupancy and

407 activity level typical of a hospital, lending credence to the idea that patient rooms with regular

408 cleaning are a harsh environment for bacteria, and that this cleaning regime is a stronger selection

409 force than sunlight exposure.

410

411 Conclusions

412 
413 This study presents initial data and trends of viable bacterial communities associated with the

414 window-components of patient rooms in a hospital. Viable Clostridioides difficile and Methicillin-

415 resistant Staphylococcus aureus, two common healthcare-associated opportunistic pathogens,

416 were not detectable and detected at very low abundance, respectively. Patient rooms with west-

417 facing windows demonstrated increased viable microbial load, and viable bacterial abundance was

418 found to be negatively correlated with patient room distance from the central nurses' station.

419 Overall, hospital window components possess similar microbial communities to other previously

420 identified room locations known to act as reservoirs for microbial agents of hospital-associated

421 infections.

422

423

424 Acknowledgments

425 The authors would like to thank Oregon Health and Science University for help in collecting 426 samples from patient rooms. The authors would like to thank Georgia MacCrone for her help in 427 processing samples. The authors would like to thank the University of Oregon Genomics and 428 Cell Characterization Core Facility (GC3F) for their expertise and resources in Next-Generation 429 sequencing. This work benefited from access to the University of Oregon high performance 430 computer, Talapas.

431

\section{Funding Statement}

433 This work was funded by membership dues of View, Inc. to the University of Oregon Institute 434 for Health in the Built Environment Industry Consortium. 


\section{References}

437 Aithinne KAN, Cooper CW, Lynch RA, Johnson DL. 2019. Toilet plume aerosol generation rate 438 and environmental contamination following bowl water inoculation with Clostridium 439 difficile spores. American journal of infection control 47:515-520. DOI: 10.1016/j.ajic.2018.11.009.

441

442

443

444

445

446

447

448

449

450

451

452

453

454

455

456

457

458

Alfa MJ, Dueck C, Olson N, Degagne P, Papetti S, Wald A, Lo E, Harding G. 2008. UV-visible marker confirms that environmental persistence of Clostridium difficile spores in toilets of patients with C. difficile-associated diarrhea is associated with lack of compliance with cleaning protocol.e. BMC infectious diseases 8:64. DOI: 10.1186/1471-2334-8-64.

Bamigboye BT, Olowe OA, Taiwo SS. 2018. Phenotypic and Molecular Identification of Vancomycin Resistance in Clinical Staphylococcus Aureus Isolates in Osogbo, Nigeria. European journal of microbiology \& immunology 8:25-30. DOI: $10.1556 / 1886.2018 .00003$

Best EL, Fawley WN, Parnell P, Wilcox MH. 2010. The potential for airborne dispersal of Clostridium difficile from symptomatic patients. Clinical infectious diseases: an official publication of the Infectious Diseases Society of America 50:1450-1457. DOI:

$$
10.1086 / 652648 \text {. }
$$

Best EL, Sandoe JAT, Wilcox MH. 2012. Potential for aerosolization of Clostridium difficile after flushing toilets: the role of toilet lids in reducing environmental contamination risk. The Journal of hospital infection 80:1-5. DOI: 10.1016/j.jhin.2011.08.010.

Boyce JM, Havill NL, Dumigan DG, Golebiewski M, Balogun O, Rizvani R. 2009. Monitoring the effectiveness of hospital cleaning practices by use of an adenosine triphosphate bioluminescence assay. Infection control and hospital epidemiology: the official journal of 
the Society of Hospital Epidemiologists of America 30:678-684. DOI: 10.1086/598243.

460 Brody T, Yavatkar AS, Lin Y, Ross J, Kuzin A, Kundu M, Fann Y, Odenwald WF. 2008.

461 Horizontal gene transfers link a human MRSA pathogen to contagious bovine mastitis

$462 \quad$ bacteria. PloS one 3:e3074. DOI: 10.1371/journal.pone.0003074.

463 Callahan BJ, McMurdie PJ, Rosen MJ, Han AW, Johnson AJA, Holmes SP. 2016a. DADA2:

464 High-resolution sample inference from Illumina amplicon data. Nature methods 13:581-

465 583. DOI: $10.1038 /$ nmeth.3869.

466 Callahan BJ, Sankaran K, Fukuyama JA, McMurdie PJ, Holmes SP. 2016b. Bioconductor

467 workflow for microbiome data analysis: from raw reads to community analyses.

468 F1000Research 5:1492. DOI: 10.12688/f1000research.8986.1.

469 Carrico R, Bryant K, Lessa F, Limbago B, Fauerbach LL, Marx JF, Sands F, Stephens D,

470 Westhusing K, Wiemken T. 2013. Guide to Preventing Clostridium difficile Infections.

$471 \quad$ DOI: $10.1016 /$ j.ajic.2010.10.011.

472 Davis NM, Proctor DM, Holmes SP, Relman DA, Callahan BJ. 2018. Simple statistical

473 identification and removal of contaminant sequences in marker-gene and metagenomics

474 data. bioRxiv:221499. DOI: 10.1101/221499.

475 Drewes JL, White JR, Dejea CM, Fathi P, Iyadorai T, Vadivelu J, Roslani AC, Wick EC,

476 Mongodin EF, Loke MF, Thulasi K, Gan HM, Goh KL, Chong HY, Kumar S, Wanyiri JW,

477 Sears CL. 2017. High-resolution bacterial 16S rRNA gene profile meta-analysis and biofilm

478 status reveal common colorectal cancer consortia. NPJ biofilms and microbiomes 3:34.

479 DOI: $10.1038 / \mathrm{s} 41522-017-0040-3$.

480 Fahimipour AK, Hartmann EM, Siemens A, Kline J, Levin DA, Wilson H, Betancourt-Román

481 CM, Brown GZ, Fretz M, Northcutt D, Siemens KN, Huttenhower C, Green JL, Van Den 
482 Wymelenberg K. 2018. Daylight exposure modulates bacterial communities associated with 483 household dust. Microbiome 6:175. DOI: 10.1186/s40168-018-0559-4.

484 Gerding DN, Muto CA, Owens RC Jr. 2008. Measures to control and prevent Clostridium 485 difficile infection. Clinical infectious diseases: an official publication of the Infectious 486 Diseases Society of America 46 Suppl 1:S43-9. DOI: 10.1086/521861.

487 Glance LG, Stone PW, Mukamel DB, Dick AW. 2011. Increases in mortality, length of stay, and 488 cost associated with hospital-acquired infections in trauma patients. Archives of surgery 489 146:794-801. DOI: 10.1001/archsurg.2011.41.

490 Greig JD, Todd ECD, Bartleson C. 2010. Infective doses and pathogen carriage. Food Safety $491 \quad$ Education.

492 Haysom IW, Sharp K. 2003. The survival and recovery of bacteria in vacuum cleaner dust. The $493 \quad$ journal of the Royal Society for the Promotion of Health 123:39-45. DOI: $494 \quad 10.1177 / 146642400312300114$.

495 Hirose S, Matsuura K, Haruta S. 2016. Phylogenetically Diverse Aerobic Anoxygenic 496 Phototrophic Bacteria Isolated from Epilithic Biofilms in Tama River, Japan. Microbes and 497 Environments 31:299-306. DOI: 10.1264/jsme2.ME15209.

498 Horve PF, Lloyd S, Mhuireach GA, Dietz L, Fretz M, MacCrone G, Van Den Wymelenberg K, 499 Ishaq SL. 2019. Building upon current knowledge and techniques of indoor microbiology to 500 construct the next era of theory into microorganisms, health, and the built environment. $501 \quad$ Journal of exposure science \& environmental epidemiology. DOI: 10.1038/s41370-019$502 \quad 0157-y$.

503 James JT. 2013. A new, evidence-based estimate of patient harms associated with hospital care. $504 \quad$ Journal of patient safety 9:122-128. DOI: 10.1097/PTS.0b013e3182948a69. 
505 Jou J, Ebrahim J, Shofer FS, Hamilton KW, Stern J, Han JH, CDC Prevention Epicenters

506 Program. 2015. Environmental transmission of Clostridium difficile: association between

507 hospital room size and C. difficile Infection. Infection control and hospital epidemiology:

508 the official journal of the Society of Hospital Epidemiologists of America 36:564-568. DOI:

$509 \quad$ 10.1017/ice.2015.18.

510 Jump RLP, Pultz MJ, Donskey CJ. 2007. Vegetative Clostridium difficile survives in room air on

511 moist surfaces and in gastric contents with reduced acidity: a potential mechanism to

512 explain the association between proton pump inhibitors and C. difficile-associated diarrhea?

513 Antimicrobial agents and chemotherapy 51:2883-2887. DOI: 10.1128/AAC.01443-06.

514 Kembel SW, Jones E, Kline J, Northcutt D, Stenson J, Womack AM, Bohannan BJ, Brown GZ,

515 Green JL. 2012. Architectural design influences the diversity and structure of the built

516 environment microbiome. The ISME journal 6:1469-1479. DOI: 10.1038/ismej.2011.211.

517 Kembel SW, Meadow JF, O’Connor TK, Mhuireach G, Northcutt D, Kline J, Moriyama M,

518 Brown GZ, Bohannan BJM, Green JL. 2014. Architectural design drives the biogeography

519 of indoor bacterial communities. PloS one 9:e87093. DOI: 10.1371/journal.pone.0087093.

520 Lax S, Sangwan N, Smith D, Larsen P, Handley KM, Richardson M, Guyton K, Krezalek M,

521 Shogan BD, Defazio J, Flemming I, Shakhsheer B, Weber S, Landon E, Garcia-Houchins S,

522 Siegel J, Alverdy J, Knight R, Stephens B, Gilbert JA. 2017. Bacterial colonization and

523 succession in a newly opened hospital. Science translational medicine 9:1-11. DOI:

$524 \quad 10.1126 /$ scitranslmed.aah6500.

525 Li M, Du X, Villaruz AE, Diep BA, Wang D, Song Y, Tian Y, Hu J, Yu F, Lu Y, Otto M. 2012.

526 MRSA epidemic linked to a quickly spreading colonization and virulence determinant.

$527 \quad$ Nature medicine 18:816-819. DOI: 10.1038/nm.2692. 
528 Love MI, Huber W, Anders S. 2014. Moderated estimation of fold change and dispersion for

529 RNA-seq data with DESeq2. Genome biology 15:550. DOI: 10.1186/s13059-014-0550-8.

530 Lu Y, Ossmann MM, Leaf DE, Factor PH. 2014. Patient visibility and ICU mortality: a

531 conceptual replication. HERD 7:92-103. DOI: 10.1177/193758671400700206.

532 Magill SS, Edwards JR, Bamberg W, Beldavs ZG, Dumyati G, Kainer MA, Lynfield R, Maloney

533 M, McAllister-Hollod L, Nadle J, Ray SM, Thompson DL, Wilson LE, Fridkin SK,

534 Emerging Infections Program Healthcare-Associated Infections and Antimicrobial Use

535 Prevalence Survey Team. 2014. Multistate point-prevalence survey of health care-

$536 \quad$ associated infections. The New England journal of medicine 370:1198-1208. DOI:

537 10.1056/NEJMoa1306801.

538 March A, Aschbacher R, Dhanji H, Livermore DM, Böttcher A, Sleghel F, Maggi S, Noale M, 539 Larcher C, Woodford N. 2010. Colonization of residents and staff of a long-term-care

540 facility and adjacent acute-care hospital geriatric unit by multiresistant bacteria. Clinical 541 microbiology and infection: the official publication of the European Society of Clinical 542 Microbiology and Infectious Diseases 16:934-944. DOI: 10.1111/j.1469$543 \quad$ 0691.2009.03024.x.

544 Mcdonald D, Ackermann G, Khailova L, Baird C, Heyland D, Kozar R, Lemieux M, Derenski

545 K, King J, Vis-Kampen C, Knight R, Wischmeyer PE. 2016. Extreme Dysbiosis of the 546 Microbiome in Critical Illness. mSphere 1:e00199-e00216. DOI: 10.1128/mSphere.00199$547 \quad 16$.

548 Meadow JF, Altrichter AE, Bateman AC, Stenson J, Brown GZ, Green JL, Bohannan BJM.

549 2015. Humans differ in their personal microbial cloud. PeerJ 3:e1258. DOI:

$550 \quad 10.7717 /$ peerj.1258. 
551 Mehtar S, FCPath MD, Hopman J, Adriano Duse MT. 2018. PATIENT AREAS AND

552 ENVIRONMENTAL CLEANING. Guide to infection control in the hospital.

553 Murphy D, Whiting J, Hollenbeak CS. 2007. Dispelling the myths: The true cost of healthcare554 associated infections. APIC 61:1-16.

555 Nocker A, Sossa-Fernandez P, Burr MD, Camper AK. 2007. Use of propidium monoazide for 556 live/dead distinction in microbial ecology. Applied and environmental microbiology

557 73:5111-5117. DOI: 10.1128/AEM.02987-06.

558

Oksanen J. 2018. Vegan: Ecological Diversity.

559 Otter JA, Yezli S, French GL. 2014. The Role of Contaminated Surfaces in the Transmission of 560 Nosocomial Pathogens. In: Borkow G ed. Use of Biocidal Surfaces for Reduction of $561 \quad$ Healthcare Acquired Infections. Cham: Springer International Publishing, 27-58. DOI: 562 10.1007/978-3-319-08057-4_3.

563

564

565

566

567

568 569

570

571

572

573

Otto M. 2013. Coagulase-negative staphylococci as reservoirs of genes facilitating MRSA infection: Staphylococcal commensal species such as Staphylococcus epidermidis are being recognized as important sources of genes promoting MRSA colonization and virulence. BioEssays: news and reviews in molecular, cellular and developmental biology 35:4-11. DOI: 10.1002/bies.201200112.

Perry C, Marshall R, Jones E. 2001. Bacterial contamination of uniforms. The Journal of hospital infection 48:238-241. DOI: 10.1053/jhin.2001.0962.

Pierce AK, Sanford JP. 1973. Bacterial contamination of aerosols. Archives of internal medicine 131:156-159.

Pittet D, Dharan S, Touveneau S, Sauvan V, Perneger TV. 1999. Bacterial contamination of the hands of hospital staff during routine patient care. Archives of internal medicine 159:821- 
826. DOI: 10.1001/archinte.159.8.821.

575 Prussin AJ 2nd, Garcia EB, Marr LC. 2015. Total Virus and Bacteria Concentrations in Indoor $576 \quad$ and Outdoor Air. Environmental science \& technology letters 2:84-88. DOI:

$577 \quad 10.1021 /$ acs.estlett.5b00050.

578 Public Health Agency of Canada. 2012.Pathogen Safety Data Sheets: Infectious Substances 579 Staphylococcus aureus - Canada.ca. Available at https://www.canada.ca/en/public580 health/services/laboratory-biosafety-biosecurity/pathogen-safety-data-sheets-risk581 assessment/staphylococcus-aureus.html (accessed January 13, 2020).

582 Qian J, Peccia J, Ferro AR. 2014. Walking-induced particle resuspension in indoor 583 environments. Atmospheric environment 89:464-481. DOI:

$584 \quad$ 10.1016/j.atmosenv.2014.02.035.

585 Quast C, Pruesse E, Yilmaz P, Gerken J, Schweer T, Yarza P, Peplies J, Glöckner FO. 2013. The 586 SILVA ribosomal RNA gene database project: improved data processing and web-based 587 tools. Nucleic acids research 41:D590-6. DOI: 10.1093/nar/gks1219.

588 Rashid T, Vonville H, Hasan I, Garey KW. 2017. Mechanisms for floor surfaces or 589 environmental ground contamination to cause human infection: a systematic review. 590 Epidemiology and infection 145:347-357. DOI: 10.1017/S0950268816002193.

591 Rogosa M. 1969. Acidaminococcus gen. n., Acidaminococcus fermentans sp. n., anaerobic 592 gram-negative diplococci using amino acids as the sole energy source for growth. Journal $593 \quad$ of bacteriology $98: 756-766$.

594 Stenson J, Ishaq SL, Laguerre A, Loia A, MacCrone G, Mugabo I, Northcutt D, Riggio M, 595 Barbosa A, Gall ET, Van Den Wymelenberg K. 2019. Monitored Indoor Environmental 596 Quality of a Mass Timber Office Building: A Case Study. Buildings 9:142. DOI: 
597

598

599

600

601

602

603

604

605

606

607

608

609

610

611

612

613

614

615

616

617

618

619

\subsection{0/buildings9060142.}

Taylor G, Gravel D, Matlow A, Embree J, LeSaux N, Johnston L, Suh KN, John M, Embil J, Henderson E, Roth V, Wong A, Canadian Nosocomial Infection Surveillance Program. 2016. Assessing the magnitude and trends in hospital acquired infections in Canadian hospitals through sequential point prevalence surveys. Antimicrobial resistance and infection control 5:19. DOI: 10.1186/s13756-016-0118-3.

Team RC, Others. 2013. R: A language and environment for statistical computing.

Turner NA, Sharma-Kuinkel BK, Maskarinec SA, Eichenberger EM, Shah PP, Carugati M, Holland TL, Fowler VG Jr. 2019. Methicillin-resistant Staphylococcus aureus: an overview of basic and clinical research. Nature reviews. Microbiology 17:203-218. DOI: $10.1038 / \mathrm{s} 41579-018-0147-4$.

Velazquez S, Griffiths W, Dietz L, Horve P, Nunez S, Hu J, Shen J, Fretz M, Bi C, Xu Y, Van Den Wymelenberg KG, Hartmann EM, Ishaq SL. 2019. From one species to another: A review on the interaction between chemistry and microbiology in relation to cleaning in the built environment. Indoor air 29:880-894. DOI: 10.1111/ina.12596.

Wang Q, Garrity GM, Tiedje JM, Cole JR. 2007. Naive Bayesian classifier for rapid assignment of rRNA sequences into the new bacterial taxonomy. Applied and environmental microbiology 73:5261-5267. DOI: 10.1128/AEM.00062-07.

Wielders CLC, Vriens MR, Brisse S, de Graaf-Miltenburg LAM, Troelstra A, Fleer A, Schmitz FJ, Verhoef J, Fluit AC. 2001. Evidence for in-vivo transfer of mecA DNA between strains of Staphylococcus aureus. The Lancet 357:1674-1675. DOI: 10.1016/S01406736(00)04832-7.

Yi L, Seo H-B. 2012. The effect of hospital unit layout on nurse walking behavior. HERD 6:66- 
621

622

623

624

625

626

627

628

629

630

631

632

633

634

635

636

637

638

639

640

641

642

643

644

645

646

647

648

649

650

651

652

653

654

655

656

657

658

Zimlichman E, Henderson D, Tamir O, Franz C, Song P, Yamin CK, Keohane C, Denham CR, Bates DW. 2013. Health care-associated infections: a meta-analysis of costs and financial impact on the US health care system. JAMA internal medicine 173:2039-2046. DOI: 10.1001/jamainternmed.2013.9763.

\section{Figure Legends}

Figure 1. Floor plan and rendering of a typical patient room at the Oregon Health and Science University hospital. (a) Floor plan of the 13th floor of Kohler Pavilion (13K) at Oregon Health and Science University (OHSU). Red shading indicates the rooms that were sampled between 10:00 a.m. and 11:00 a.m. on June 7, 2019 (b) Digital rendering of a typical patient room on OHSU $(13 \mathrm{~K})$ with the sampling locations indicated by the numbers. The sampled locations were (1) window glass surface, (2) the window frame surface facing into the room at the sill, (3) glazing-side of the window frame at the sill, (4) window-side of the curtain, (5) patient-side of the curtain and, (6) wood-covered air return grille.

Figure 2. Absolute abundance of bacteria at sampling locations around windows within hospital patient rooms. Each point represents an individual sample, calculated as qPCR-based estimates of $\log _{10}$-transformed copies of the $16 \mathrm{~S}$ rRNA gene. Abundance shown by (a) room sampling locations, including air vents (red), curtains (green), windows (turquoise), and window sills (purple); by (b) relative light exposure, including surfaces in indirect sunlight (navy blue) and direct sunlight (yellow); and by (c) window orientation of cardinal direction, colors are the same as in panel (a).

Figure 3. Absolute abundance of bacteria around windows by room across a hospital ward. Absolute bacterial abundance was calculated with qPCR-based estimates of $\log _{10}$-transformed copies of the $16 \mathrm{~S}$ rRNA gene. Abundance at all sampled locations within the patient room were summed to obtain total bacteria abundance. Abundance is shown (a) overlaid on a floor plan of ward $13 \mathrm{~K}$ at OHSU and (b) as a function of the distance of each room from the centrally-located nurse station on their half of the floor.

Figure 4. Alpha diversity of viable bacterial communities from locations around hospital room windows. Shannon diversity ( $\left.\mathrm{H}^{\prime}\right)$ from (a) surfaces in indirect sunlight (navy blue) and direct sunlight (yellow); and (b) from room sampling locations, including curtains (red), window sills (green), air return vents (turquoise), and windows (purple). 
659 Figure 5. Differentially abundant bacteria between sampling locations. (a) - ( f)

660 Differentially abundant taxa between locations as determined using DESeq2. (g) Heatmap

661 showing relative abundances of viable discriminant taxa. Warmer colors correspond to higher

662 abundances; white tiles indicate those taxa were not detected in particular samples (columns).

663 Columns are individual viable environmental sample communities, where sampling location is

664 indicated by the labels on the $\mathrm{x}$-axis.

665

666

667

668

669

670

671

672

673

674

675

676

677

678

679

680

\section{Supporting Information}

\section{Table S1 DNA sequences for qPCR standards.}

Table S2. Data summary statistics for bacterial abundance for rooms facing each direction.

Figure S1. Community composition of viable bacterial communities. (a) Pie charts of the 25 most abundant viable bacteria broken down by their Genus in direct sunlight (top) and indirect sunlight (bottom). (b) Pie charts of the 25 most abundant viable bacteria broken down by their Genus on the surface of curtains, windows, window sills, and air return vents respectively (top to bottom). (c) Relative abundance of the identified phyla on each surface tested (left) and in each lighting condition (right). (d) 25 most abundant Genera and their respective relative abundance on each surface tested (left) and in each lighting condition (right). 


\section{Figure 1}

Floor plan and rendering of a typical patient room at the Oregon Health and Science University hospital.

(a) Floor plan of the 13th floor of Kohler Pavilion (13K) at Oregon Health and Science University (OHSU). Red shading indicates the rooms that were sampled between 10:00 a.m. and 11:00 a.m. on June 7, 2019 (b) Digital rendering of a typical patient room on OHSU (13K) with the sampling locations indicated by the numbers. The sampled locations were (1) window glass surface, (2) the window frame surface facing into the room at the sill, (3) glazing-side of the window frame at the sill, (4) window-side of the curtain, (5) patient-side of the curtain and, (6) wood-covered air return grille. 


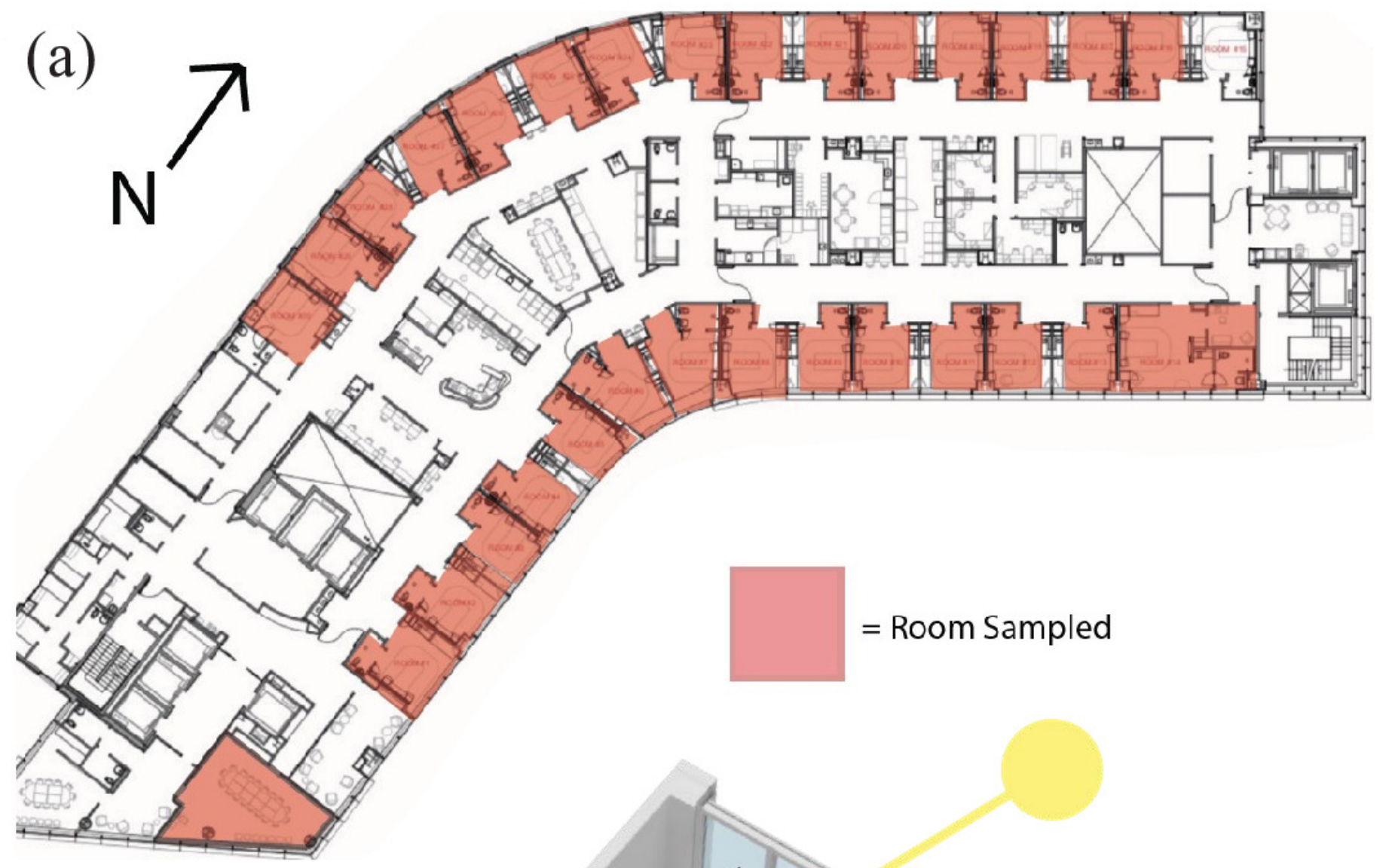

(b)

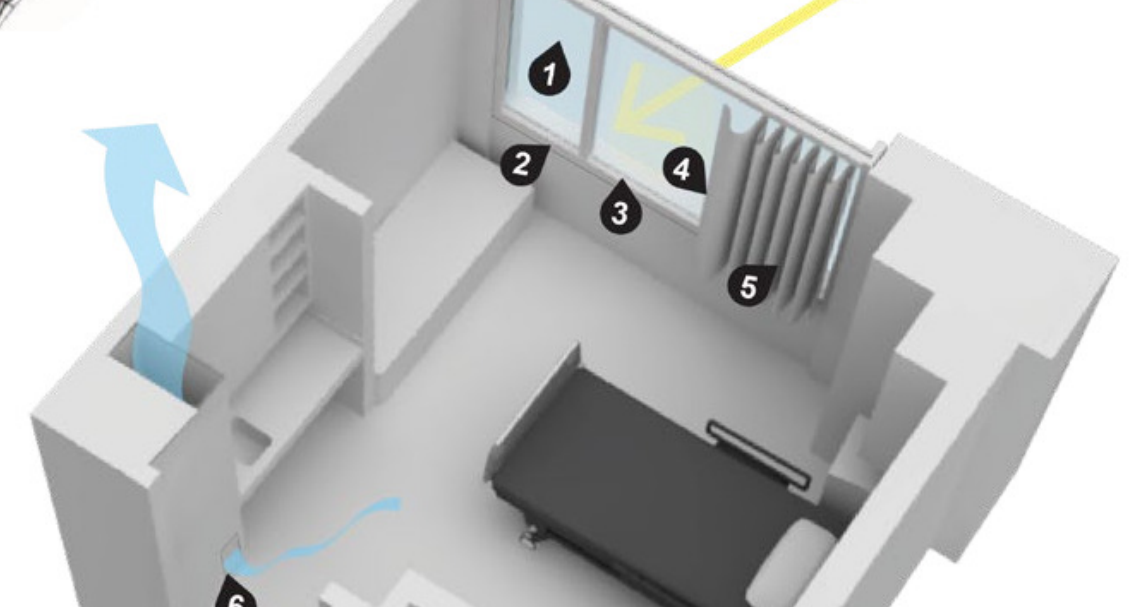




\section{Figure 2}

Absolute abundance of bacteria at sampling locations around windows within hospital patient rooms.

Each point represents an individual sample, calculated as qPCR-based estimates of $\log _{10^{-}}$ transformed copies of the 16S rRNA gene. Abundance shown by (a) room sampling locations, including air vents (red), curtains (green), windows (turquoise), and window sills (purple); by (b) relative light exposure, including surfaces in indirect sunlight (navy blue) and direct sunlight (yellow); and by (c) window orientation of cardinal direction, colors are the same as in panel (a). 
(a)

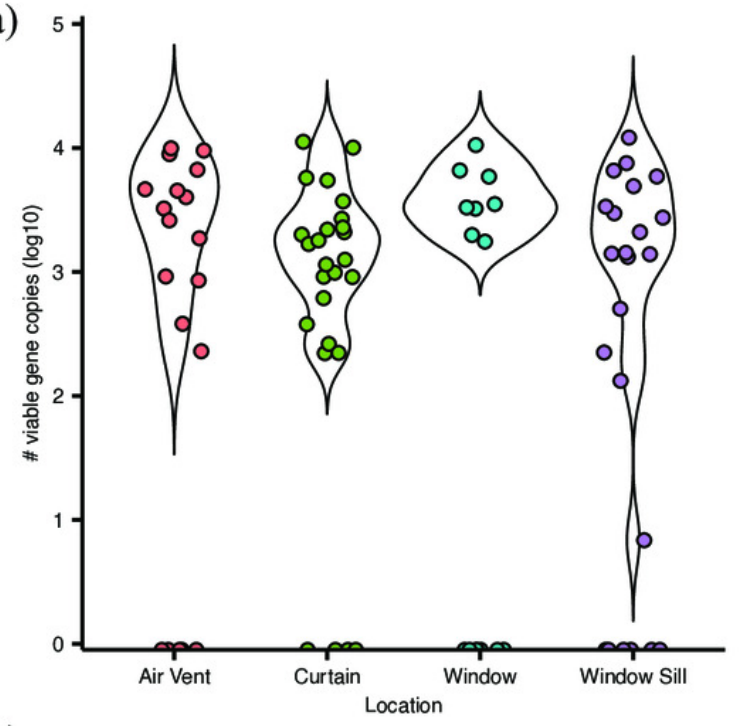

(b)

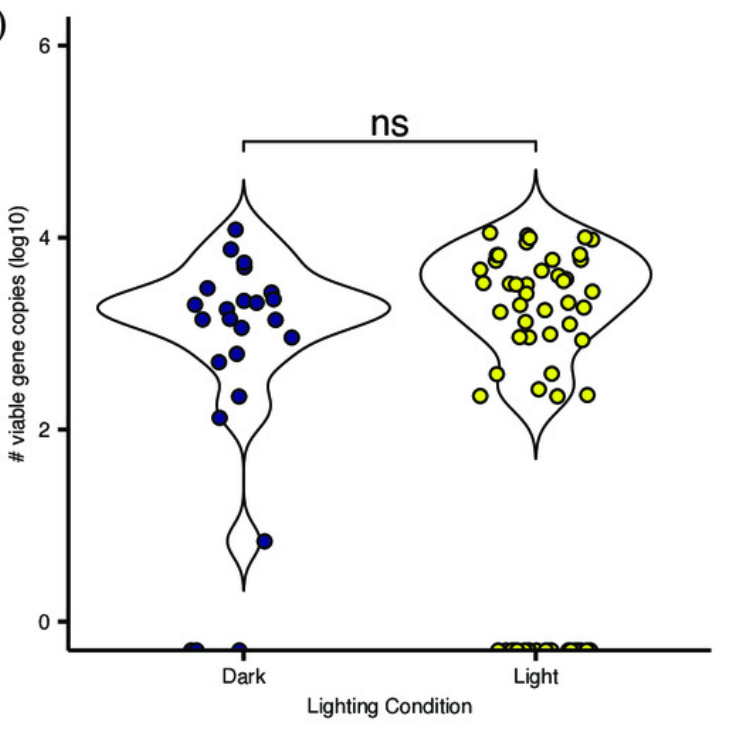

(c)

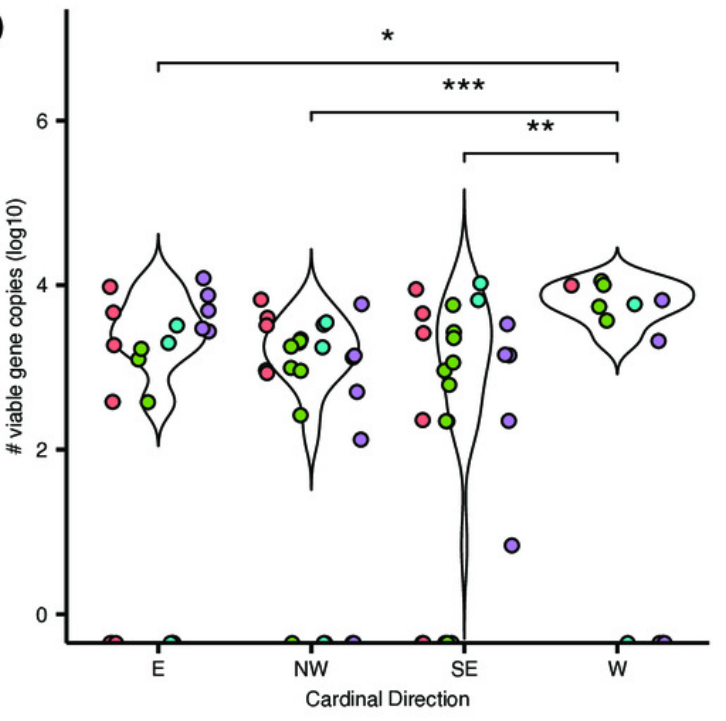


Figure 3

Absolute abundance of bacteria around windows by room across a hospital ward Absolute bacterial abundance was calculated with qPCR-based estimates of $\log _{10}$-transformed copies of the 16S rRNA gene. Abundance at all sampled locations within the patient room were summed to obtain total bacteria abundance. Abundance is shown (a) overlaid on a floor plan of ward $13 \mathrm{~K}$ at OHSU and (b) as a function of the distance of each room from the centrally-located nurse station on their half of the floor.

(a)

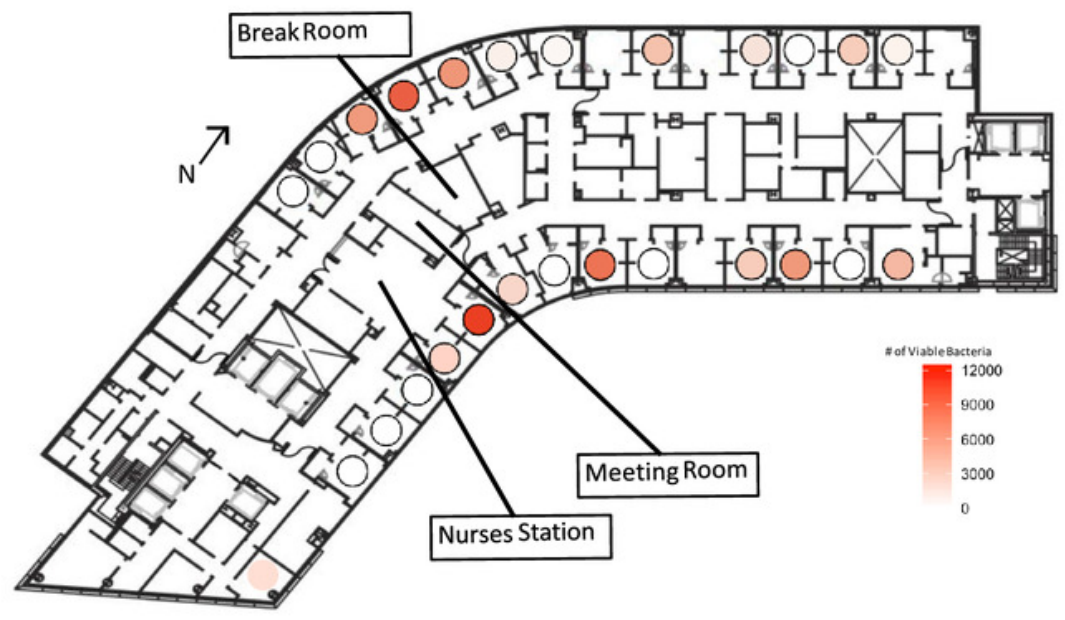

(b)

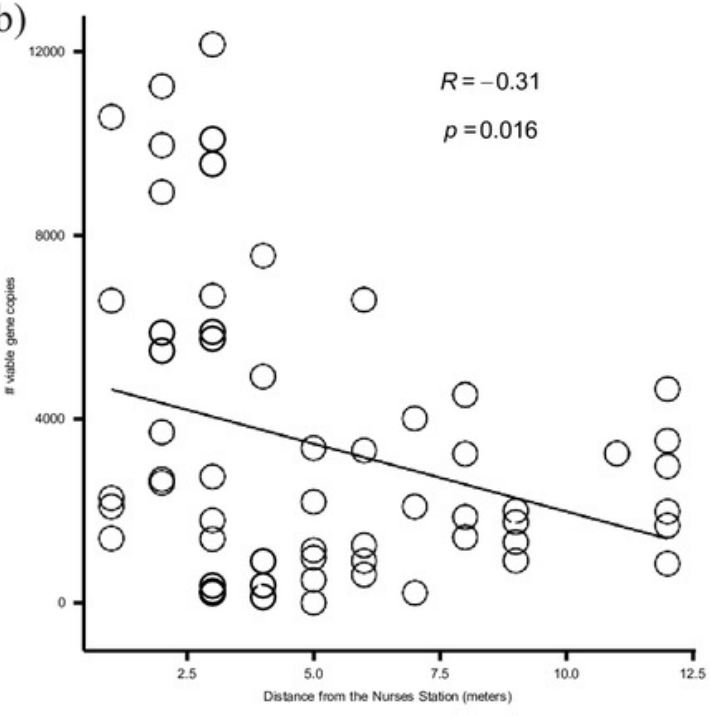


Figure 4

Alpha diversity of viable bacterial communities from locations around hospital room windows.

Shannon diversity $\left(H^{\prime}\right)$ from (a) surfaces in indirect sunlight (navy blue) and direct sunlight (yellow); and (b) from room sampling locations, including curtains (red), window sills (green), air return vents (turquoise), and windows (purple). 
(a)

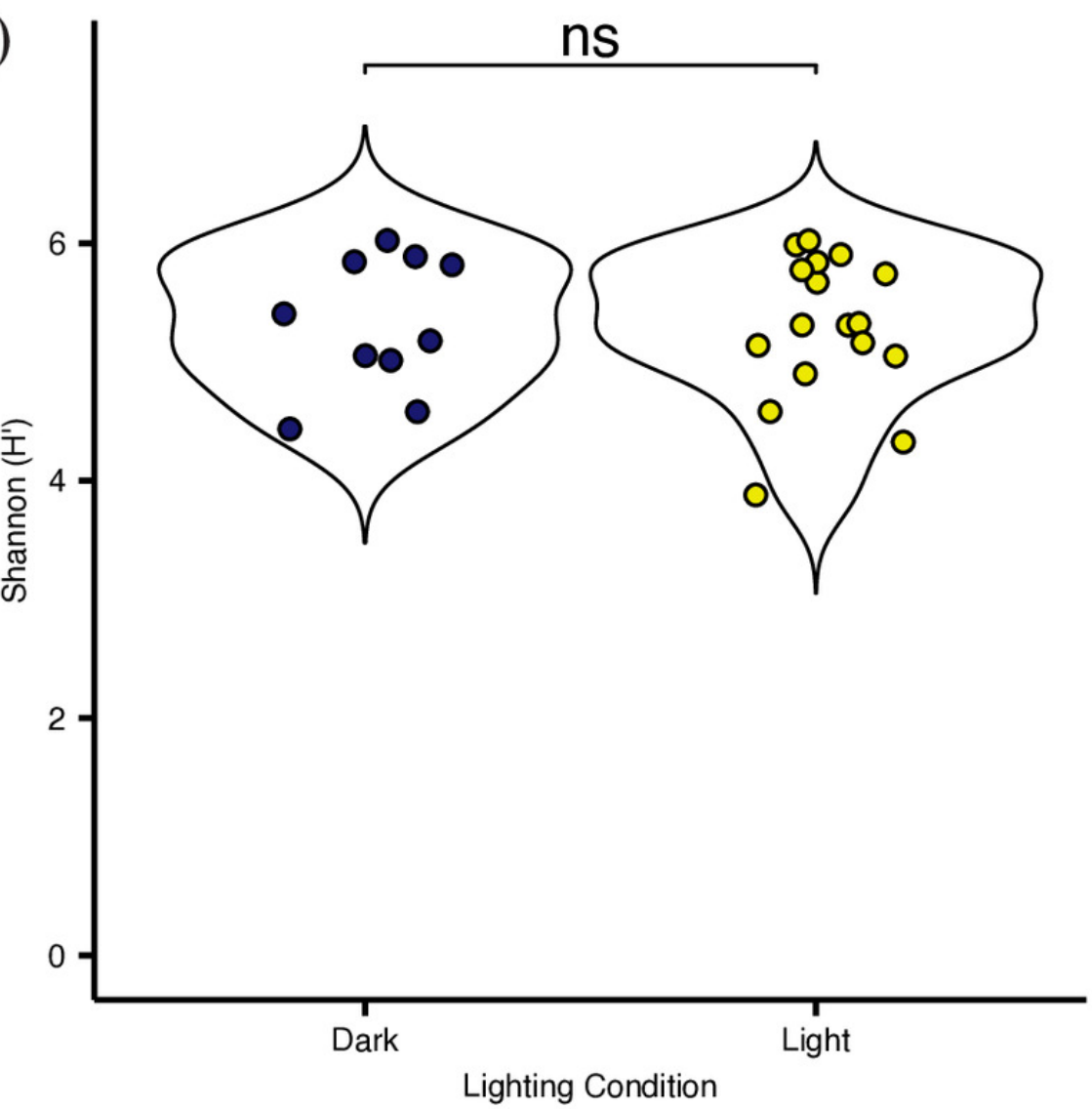

(b)

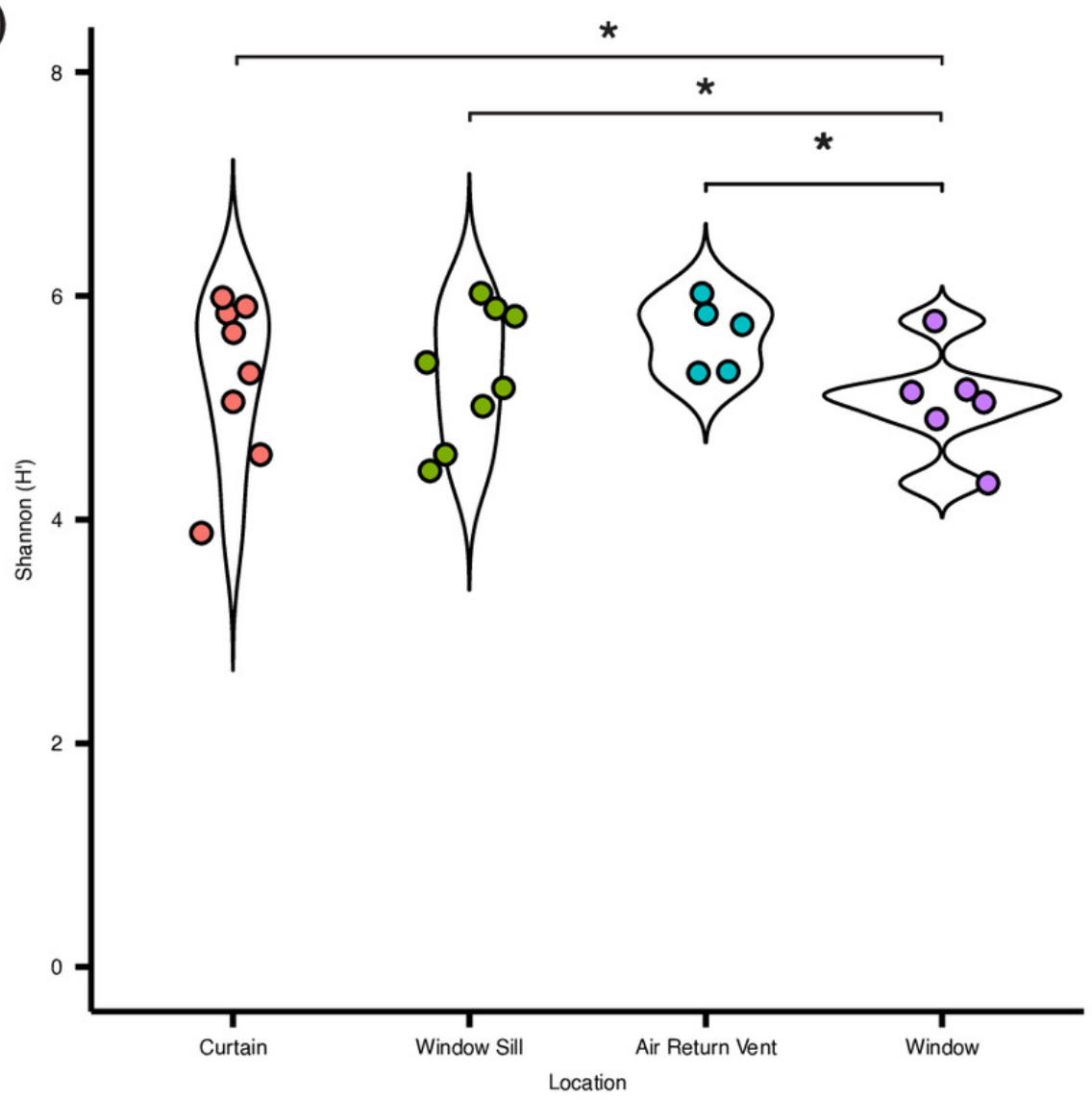




\section{Figure 5}

Differentially abundant bacteria between sampling locations.

(a) - ( f) Differentially abundant taxa between locations as determined using DESeq2. (g) Heatmap showing relative abundances of viable discriminant taxa. Warmer colors correspond to higher abundances; white tiles indicate those taxa were not detected in particular samples (columns). Columns are individual viable environmental sample communities, where sampling location is indicated by the labels on the $\mathrm{x}$-axis. 

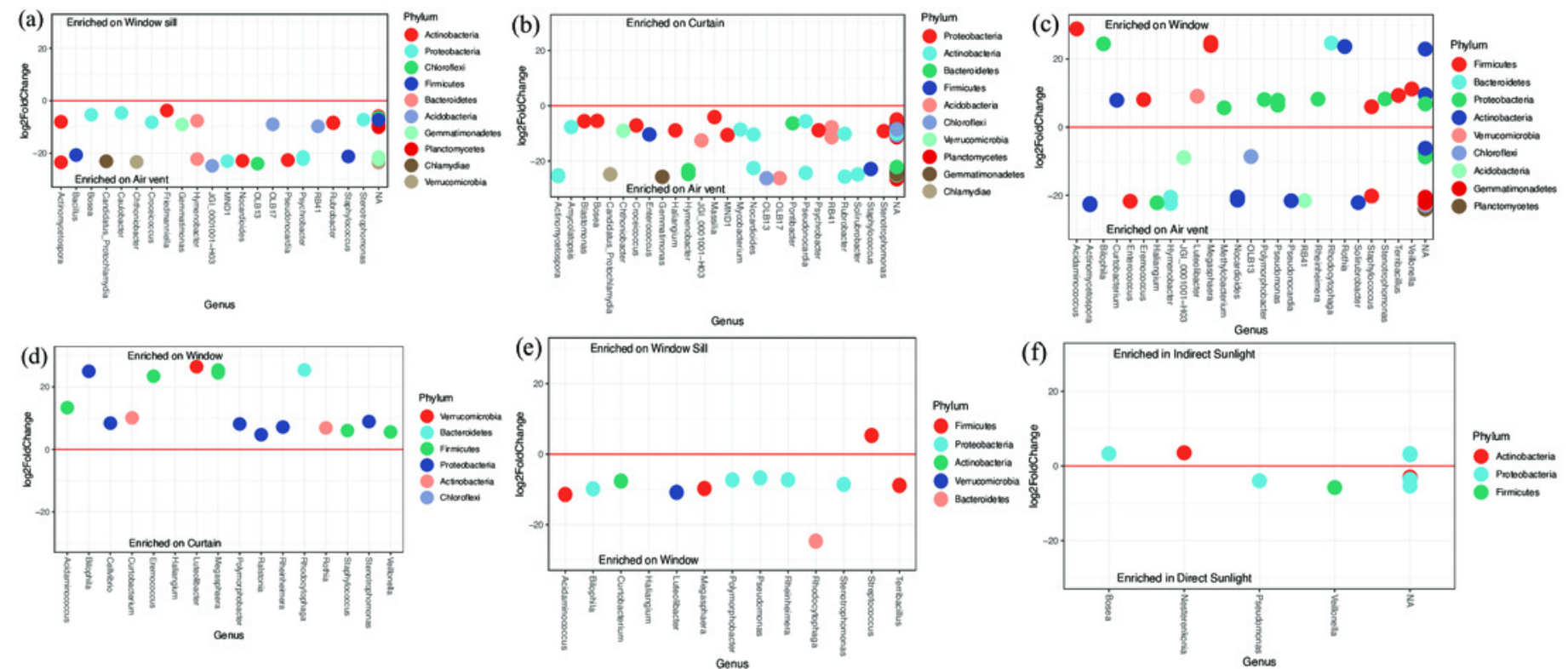

(g)

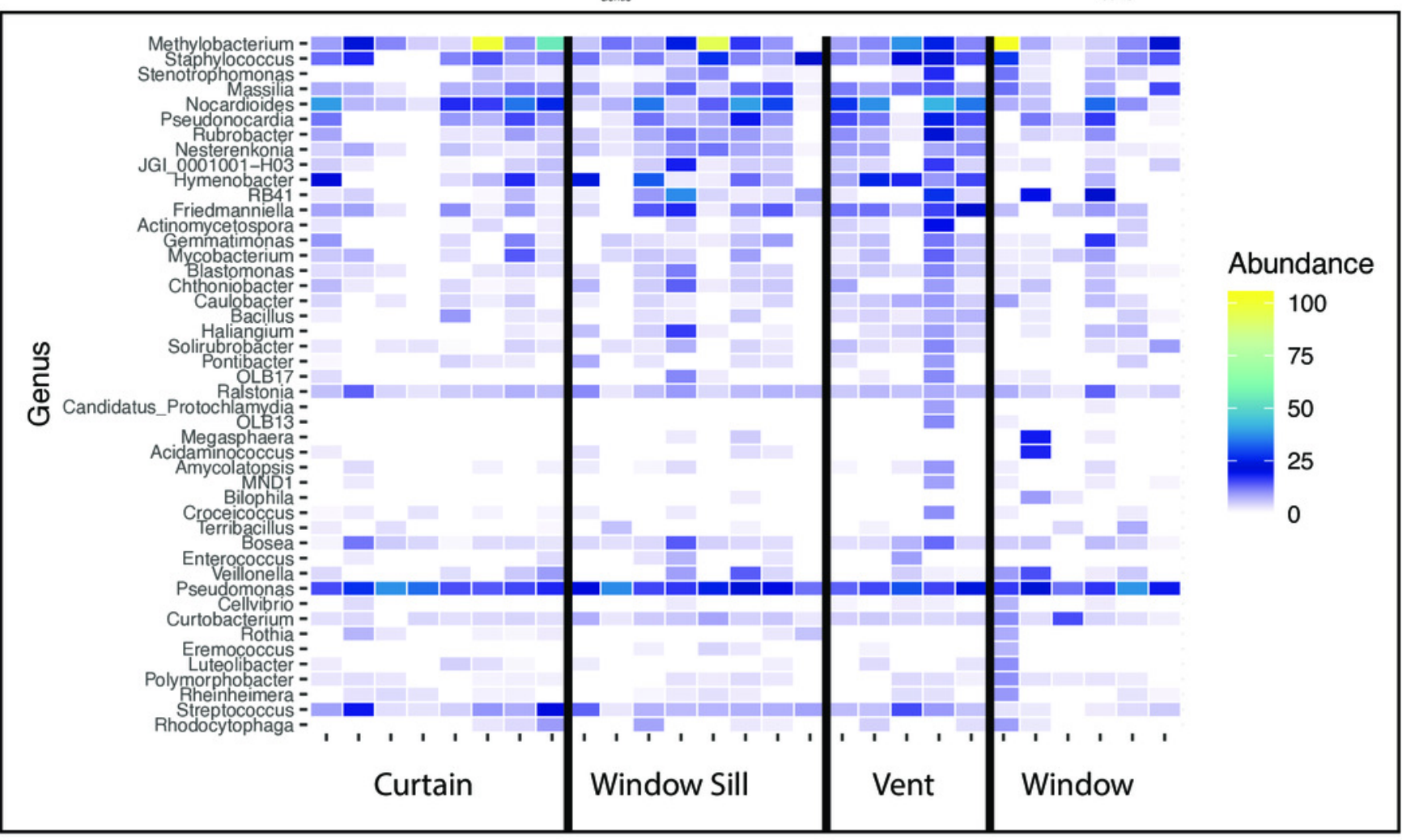

